\title{
Predicting Small-Scale, Short-Lived Downbursts: Case Study with the NWP Limited-Area ALARO Model for the Pukkelpop Thunderstorm
}

\author{
Pieter De MeutTer \\ Royal Meteorological Institute of Belgium, Brussels, and Department of Physics and Astronomy, \\ Ghent University, Ghent, Belgium \\ Luc Gerard, Geert Smet, Karim Hamid, Rafiq Hamdi, and DaAn Degrauwe \\ Royal Meteorological Institute of Belgium, Brussels, Belgium \\ PIET TERMONIA \\ Royal Meteorological Institute of Belgium, Brussels, and Department of Physics and Astronomy, \\ Ghent University, Ghent, Belgium
}

(Manuscript received 12 September 2014, in final form 31 October 2014)

\begin{abstract}
The authors consider a thunderstorm event in 2011 during a music festival in Belgium that produced a shortlived downburst of a diameter of less than $100 \mathrm{~m}$. This is far too small to be resolved by the kilometric resolutions of today's operational numerical weather prediction models. Operational forecast models will not run at hectometric resolutions in the foreseeable future. The storm caused five casualties and raised strong societal questions regarding the predictability of such a traumatic weather event.

In this paper it is investigated whether the downdrafts of a parameterization scheme of deep convection can be used as proxies for the unresolved downbursts. To this end the operational model ALARO [a version of the Action de Recherche Petite Echelle Grande Echelle-Aire Limitée Adaptation Dynamique Développement International (ARPEGE-ALADIN) operational limited area model with a revised and modular structure of the physical parameterizations] of the Royal Meteorological Institute of Belgium is used. While the model in its operational configuration at the time of the event did not give a clear hint of a downburst event, it has been found that (i) the use of unsaturated downdrafts and (ii) some adaptations of the features of this downdraft parameterization scheme, specifically the sensitivity to the entrainment and friction, can make the downdrafts sensitive enough to the surrounding resolved-scale conditions to make them useful as indicators of the possibility of such downbursts.
\end{abstract}

\section{Introduction}

On 18 August 2011, several convective cells developed over northern France and Belgium. The cells merged into a bow echo with bookend vortex, which struck the Pukkelpop music festival. At that moment 60000 people were present. In a time span of $10 \mathrm{~min}$, the festival was swept by heavy rain, hail with a diameter of $1-2 \mathrm{~cm}$, and strong wind gusts. Trees were uprooted, festival light towers and video screens were knocked down, and one of the concert tents collapsed. A total of 5 people were killed, and at least 140 were injured.

Corresponding author address: Pieter De Meutter, Royal Meteorological Institute of Belgium, Ringlaan 3,1180 Brussels, Belgium. E-mail: pieter.demeutter@meteo.be
Weather stations in Belgium measured up to $70 \mathrm{~mm}$ of accumulated precipitation. The highest wind gusts were measured by the automatic weather station (AWS) of Diepenbeek, Belgium, at a distance of $8 \mathrm{~km}$ from the Pukkelpop festival, recording a peak gust of $23 \mathrm{~m} \mathrm{~s}^{-1}$. The wind gusts at the festival were estimated to range between 29 and $37 \mathrm{~m} \mathrm{~s}^{-1}$ and the storm was accompanied by heavy precipitation and hail.

We made a survey at the Pukkelpop festival afterward. While many trees were uprooted, the damage on nearby residences was found to be marginal. Because of the fragmented nature and the pattern of damage, and the fact that the fallen trees were all pointing in the same direction, it is fully excluded that the damage was caused by a tornado; instead it should be attributed to exceptionally strong downdrafts. Moreover, the diameter of the track had 
a width of less than $100 \mathrm{~m}$. This satisfies the definition of a short-lived downburst as put forth by Fujita (1981).

It is impossible to resolve a 100 -m-wide downburst with current operational numerical weather prediction models. Deep convective parameterization schemes can be used within models to take into account the effects of subgrid convective processes, but $100 \mathrm{~m}$ is at least one order of magnitude smaller than the current maximal resolutions of a few kilometers used in today's operational models. However, given the impact of this event, any indicator of a possibility of subgrid downbursts that can be derived from the output of today's weather prediction models is useful to complement our warning systems for such cases. Here we investigate whether the subgrid downdraft speed of a parameterization scheme of deep convection can be used as a proxy for the possibility of unresolved downburst events.

Of course, one can always recalibrate the models to make the downdrafts stronger, but this can lead to overcalibration and might degrade the behavior of the model in other situations. Moreover, there are no observations available of the vertical velocities or the mass fluxes during this event. So (i) for their values one can only rely on the literature such as given by Fujita and Wakimoto (1983), and (ii) one can rely on secondary effects caused by the deep convection that are either resolved or that can be observed, to recalibrate the deep convection scheme. Given the huge jump in resolution from the kilometric to the hectometric scales, it cannot be hoped a priori to have a full representation of the strength of the downburst, but if its strength is sufficiently sensitive to the specificities of the situation, it could be used as a proxy to provide extra guidance for forecasters. In this case it means that higher subgrid downdraft values should be reproduced in case of the Pukkelpop event, but not in other cases where convection took place but where we are sure it did not lead to such documented downburst cases.

A well-observable secondary effect to be used for calibration is the cold pool mechanism. Precipitationcooled air in the downdraft sinks and forms a cold pool at the surface. Several precipitating thunderstorms can form a coherent cold pool with a horizontal diameter of the order of $100 \mathrm{~km}$ (Fujita 1959; Johnson and Hamilton 1988). From soundings, a cold pool depth of $3 \mathrm{~km}$ is found to be common for mesoscale convective systems (MCSs) in the central United States (Bryan et al. 2005). It is not known how broadly applicable these depths are to smaller-scale storms or in other regional environments. The descending cold air causes a pressure increase at the surface, called a surface mesohigh, of which the strength depends on the temperature and depth of the cold pool (Wakimoto 1982). Engerer et al. (2008) investigated the surface characteristics of cold pools from MCS using observations from the Oklahoma Mesonet. They found a mean temperature drop of $7 \mathrm{~K}$ and a pressure rise of $4.5 \mathrm{hPa}$ for mature stage MCS. They suggest that if the model fails to represent cold pool characteristics correctly, improvements to the model physical parameterizations may be needed.

Another secondary effect is the wind gusts. Gusty winds in the cold pool originate from downward momentum transport and surface pressure perturbations (e.g., Vescio and Johnson 1992). Furthermore, mesoscale vortices can play a role in generating low-level wind gusts near squall lines and bow echoes (Atkins et al. 2004; Wakimoto et al. 2006; Wheatley and Trapp 2008; Atkins and St. Laurent 2009).

Finally, the strength of the downburst should be, in principle, resolved better when increasing the model resolution. So if the model is run without parameterization of deep convection and the resolution is increased, then the sensitivity of the vertical velocities to the synoptic-scale conditions should be improved.

The methodology used in the present paper starts from the operational model output of the ALARO model [a version of the Action de Recherche Petite Echelle Grande Echelle-Aire Limitée Adaptation Dynamique Développement International (ARPEGEALADIN) operational limited area model with a revised and modular structure of the physical parameterizations] of the Royal Meteorological Institute (RMI) of Belgium that was running with a horizontal grid spacing of $4 \mathrm{~km}$ operationally that time. However, the operationally forecasted precipitation rates were an order of magnitude smaller than the observed values. Inspecting the values of the subgrid downdraft velocities, it was found that they did not show spatial patterns that gave an indication of an extreme event at the location of the festival. Therefore, we have modified the downdraft scheme in two steps: 1) we allowed the downdrafts to be unsaturated and 2) we calibrated the downdraft scheme by changing the sensitivity to the entrainment and the friction to better capture the secondary effect of the cold pool. In the present paper only the tests with the unsaturated downdrafts will be discusses in detail.

As a supplementary sanity check, the newly found values of the downdraft mass fluxes will be compared with those of a 1-km grid spacing run; not to check the values in absolute sense [since deep convection is not fully resolved at 1-km grid spacing; Bryan et al. (2003)], but to verify whether their sensitivity to the resolvedscaled conditions is improved and to check that the speed of the downdrafts is not excessively large in nonsevere convective cases. Finally, it is verified that the 


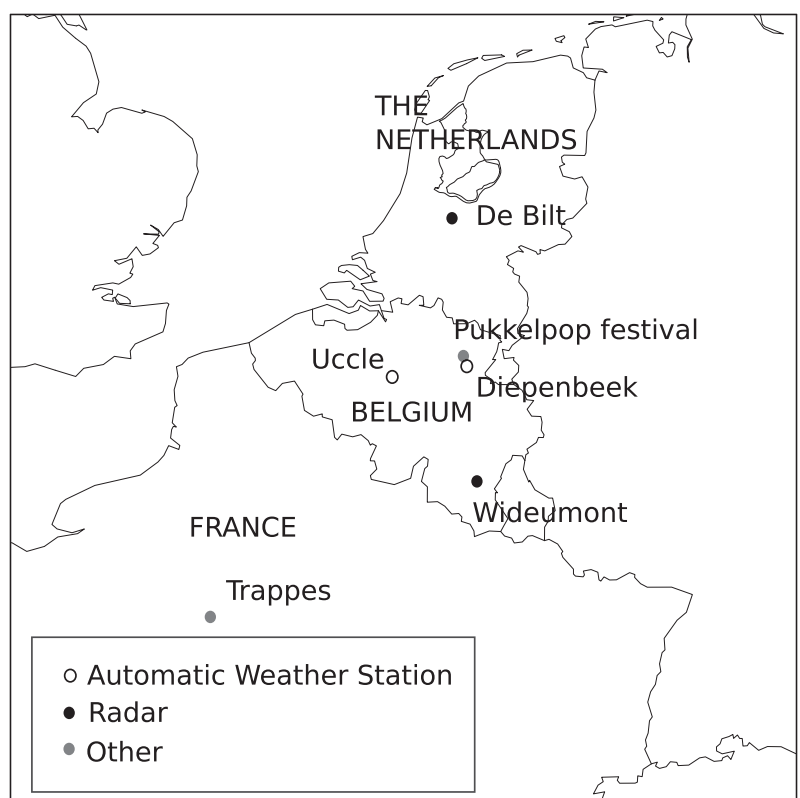

FIG. 1. Map with geographical names and the locations of automatic weather stations, radars, and sounding stations.

behavior of the model stays neutral in terms of standard average scores.

This paper is organized as follows. Section 2 gives a description of the observations and the used model (i.e., the ALARO model). Section 3 discusses the meteorological situation of 18 August 2011. The calibration of the downdraft scheme is discussed in section 4. In section 5, the parameterized downdraft is compared with the resolved downdraft and it is shown that the recalibrated downdraft scheme does not deteriorate average model behavior. Conclusions are given in section 6 .

\section{Observations and model}

\section{a. Observations}

Observations were made by automatic weather stations (AWSs) over Belgium and single-polarization C-band Doppler radars at De Bilt, the Netherlands, and Wideumont, Belgium [for the latter, see e.g., Delobbe and Holleman (2006)]. The locations of some of the stations and radars are shown in Fig. 1.

\section{b. Simulations}

\section{1) ALARO MODEL}

The Pukkelpop storm has been simulated using the limited-area model ALARO [see De Troch et al. (2013) for a description of the scientific content of the model]. ALARO uses a vertical staggered grid with physical quantities defined on the model layers, and fluxes defined on the interface between two model layers. Every three hours, lateral boundary conditions are provided by the global and spectral numerical weather prediction model, Action de Recherche Petite Echelle Grande Echelle (ARPEGE) from Météo-France.

To take into account the subgrid effects of convection, a package called Modular Multiscale Microphysics and Transport (3MT) is used (Gerard et al. 2009). 3MT has been developed to deal with the "gray zone" problem: at grid spacings between 7 and $2 \mathrm{~km}$, models partly resolve convection. At these resolutions, excessive precipitation is predicted when convection is treated explicitly (Deng and Stauffer 2006). Most parameterizations on the other hand have been built assuming large grid spacings and long time steps. Moreover, they often treat precipitation and clouds in a diagnostic way, leading to problems such as an intermittent on-off behavior of deep convection at finer resolution and shorter time steps. 3MT uses a prognostic treatment of subgrid updraft and downdraft velocity $\left(\omega, \mathrm{Pa} \mathrm{s}^{-1}\right)$ and mesh fraction $(\sigma$, dimensionless number between 0 and 1$)$, together with a specific organization of the parameterizations and their interaction. The mass flux that is actually felt by the resolved flow is $\omega \times \sigma / g$ (with $g$ the gravitational acceleration). In this paper, the use of the downdraft $\omega / g$ as a proxy for downbursts is explored. We do not use $\omega \times \sigma / g$ as a proxy because it can highlight weak downdrafts with large widths, which are not associated with downbursts.

The 3MT scheme was used operationally in 2011 with saturated downdrafts. The saturated downdraft very often produces high $\omega$ values, accompanied by mostly negligible $\sigma$, so that although giving realistic $\omega \times \sigma$, the saturated downdraft scheme predicts $\omega$, which cannot be used as a proxy for downbursts (see further discussion in section 5). As mentioned in the introduction, a new version of this scheme with unsaturated downdrafts has been used and is described below.

TABLE 1. Some features of the different model runs [hydrostatic (HS) and nonhydrostatic (NH)].

\begin{tabular}{|c|c|c|c|c|c|c|}
\hline Name & $\begin{array}{l}\text { Horizontal grid } \\
\text { spacings }(\mathrm{km})\end{array}$ & $\begin{array}{l}\text { Horizontal grid } \\
\text { points }\end{array}$ & Vertical levels & $\mathrm{HS} / \mathrm{NH}$ & $\begin{array}{c}\text { Convective } \\
\text { parameterization }\end{array}$ & Time step (s) \\
\hline fc4 & 4 & $181 \times 181$ & 46 & HS & Yes & 180 \\
\hline fc4_tun & 4 & $181 \times 181$ & 46 & HS & Yes & 180 \\
\hline fc1 & 1 & $469 \times 469$ & 60 & $\mathrm{NH}$ & No & 30 \\
\hline
\end{tabular}




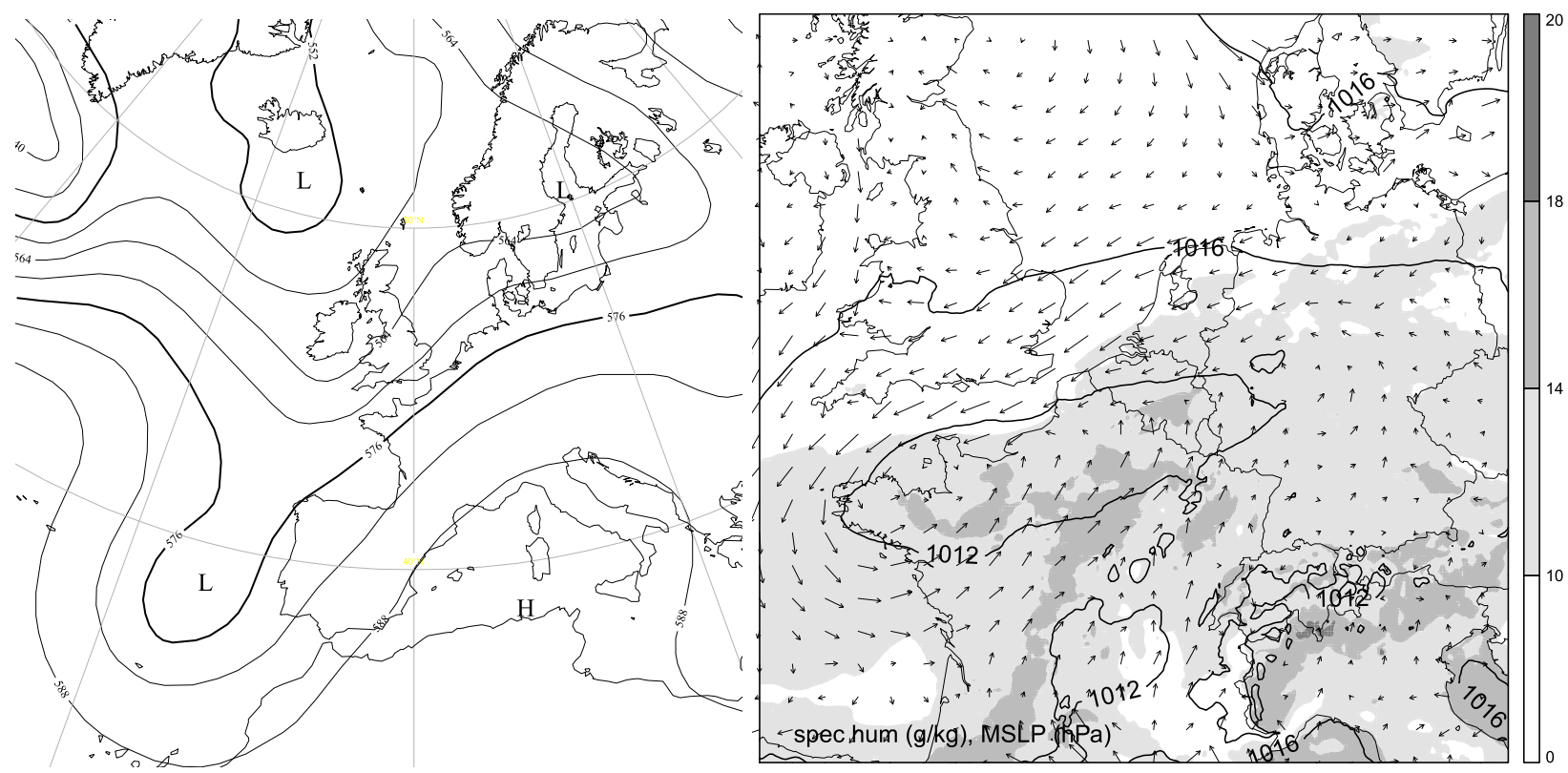

FIG. 2. Analysis for 1200 UTC 18 Aug 2011. (left) ECMWF analysis showing the 500-hPa geopotential height (dam) and (right) ALARO analysis showing mean sea level pressure (contours, hPa), 2-m specific humidity (shaded, $\mathrm{g} \mathrm{kg}^{-1}$ ), and 10-m wind vectors.

The starting level for the downdraft is taken as the first minimum in the moist static energy below $500 \mathrm{hPa}$, since the strongest potential downdrafts start around the level of minimal equivalent potential temperature $\theta_{e}$ at approximately $650 \mathrm{hPa}$ (Sud and Walker 1993). The mean gridbox wet bulb properties are taken as a starting point. Following the ideas of Betts and Silva Dias (1979), it is assumed that in its descent between two adjacent model levels, the downdraft follows a curve of constant $\theta_{e}$, although remaining unsaturated:

$$
\frac{1}{\theta_{e}} \frac{d \theta_{e}}{d p}=0=\frac{1}{\theta_{\mathrm{dd}}} \frac{d \theta_{\mathrm{dd}}}{d p}+\frac{L}{c_{p} T_{\mathrm{dd}}} \frac{d q_{\mathrm{dd}}}{d p},
$$

where $\theta_{\mathrm{dd}}$ is the potential temperature in the downdraft, $L$ is the latent heat of evaporation, $c_{p}$ is the heat capacity of air at constant pressure, $T_{\mathrm{dd}}$ is the temperature in the downdraft, and $q_{\mathrm{dd}}$ is the specific humidity in the downdraft. In addition, at each level the unsaturated downdraft has the same equivalent potential temperature as the saturated downdraft since $L\left(q_{s}-q_{\mathrm{dd}}\right)=$ $c_{p}\left(T_{\mathrm{dd}}-T_{s}\right)$, where $T_{s}$ and $q_{s}$ denote the saturated downdraft temperature and specific humidity, respectively. Entrainment is applied at constant pressure between each descent segment and can alter $\theta_{e}$. The entrainment rate is constant along the vertical and is parameterized by $\lambda_{\mathrm{dd}}$. A nondimensional entrainment coefficient $\xi$ is expressed as follows:

$$
\xi^{\prime \overline{l-1}}=\lambda_{\mathrm{dd}}\left(\phi^{l-1}-\phi^{l}\right),
$$

$\psi_{\mathrm{dd}}^{l}=\psi_{\mathrm{dd}}^{l-1}+\xi^{\overline{l-1}}\left(\psi_{e}^{l-1}-\psi_{\mathrm{dd}}^{l}\right)$

$$
\psi_{\mathrm{dd}}^{l}=\psi_{\mathrm{dd}}^{l-1}+\xi^{\overline{l-1}}\left(\psi_{e}^{l-1}-\psi_{\mathrm{dd}}^{l-1}\right) \quad \text { with: } \xi=\frac{\xi^{\prime}}{1+\xi^{\prime}},
$$

where $\phi^{l}$ is the geopotential of model level $l$ and $\psi^{l}$ is a physical variable at model level $l$. The subscript dd stands for downdraft, and $e$ for environment. The model levels are numbered from top to bottom, $l$ stands for the center of the model layer $l$ and $\bar{l}$ its lower interface, between $l$ and $l+1$. The downdraft specific humidity is changed by entrainment and evaporation. The unresolved downdraft width is taken to be one-third of the precipitating area inside a grid box.

The effect of drag and entrainment is represented in the vertical momentum equation as follows:

$$
\frac{\partial \omega_{\mathrm{dd}}}{\partial t}=-\left(\lambda_{\mathrm{dd}}+\frac{K_{\mathrm{dd}}}{g}\right) \frac{1}{\rho} \omega_{\mathrm{dd}}^{2}+\text { other terms },
$$

where the entrainment rate $\lambda_{\mathrm{dd}}$ and the drag $K_{\mathrm{dd}}$ are the main parameters that need to be calibrated, since these are the most sensitive parameters we have in our downdraft scheme that can affect the downdraft intensity; $g$ stands for the gravitational acceleration. The other terms include buoyancy, vertical subgrid advection, and braking toward the surface [see Gerard (2007)]. The unsaturated downdraft properties (and the buoyancy) result from the budget between the adiabatic warming and the evaporative cooling, so that an 


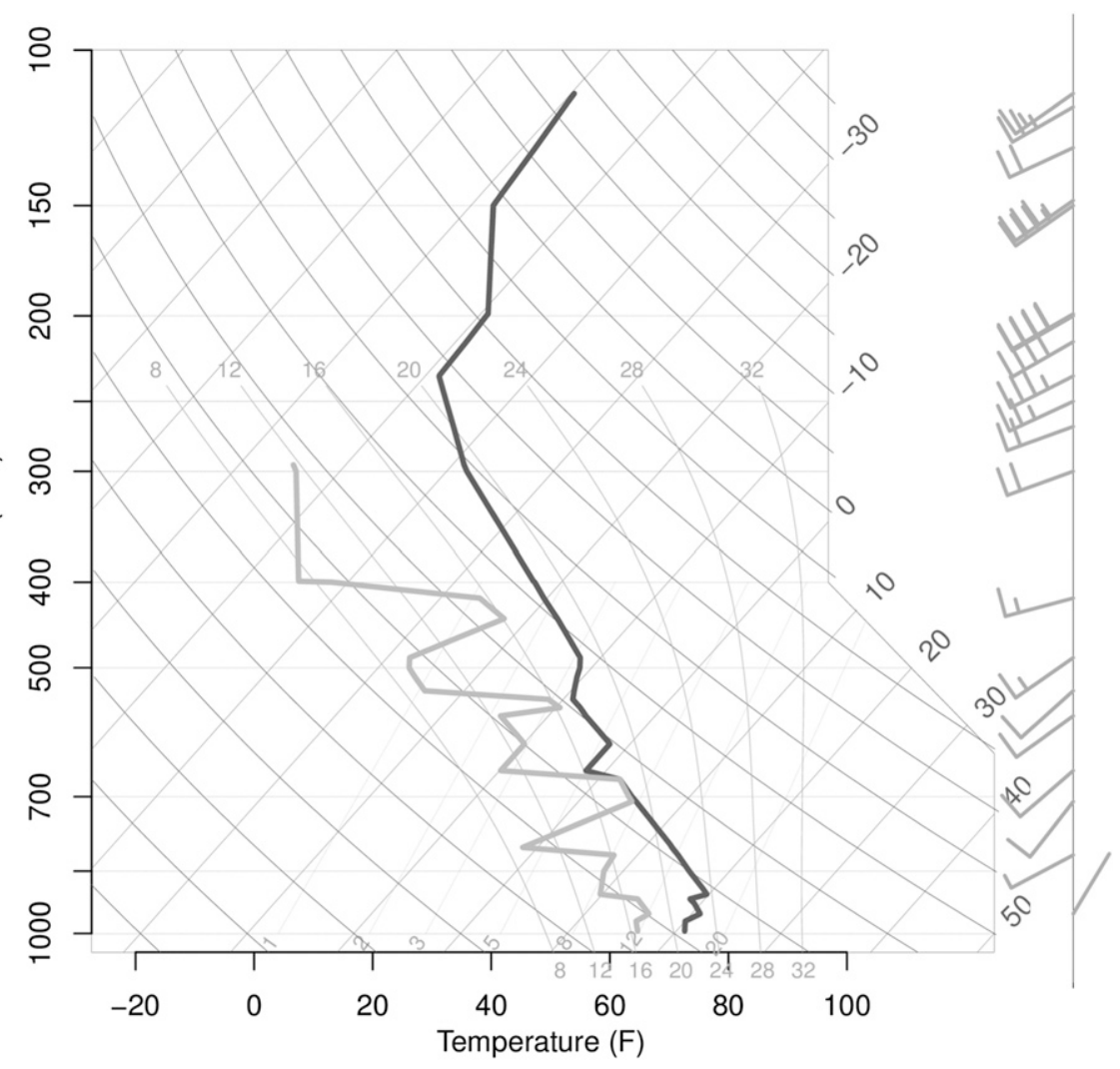

FIG. 3. Sounding at 0000 UTC 18 Aug 2011 from the radiosonde station Trappes (data from http://weather.uwyo.edu). (from bottom-left corner to top-right corner) Thin straight lines: isotherms $\left({ }^{\circ} \mathrm{F}\right.$, horizontal axis, and ${ }^{\circ} \mathrm{C}$, right vertical axis); thick lines: environmental temperature (black) and dewpoint (gray); and thin bending curves: dry adiabatic and saturated adiabatic lines. Pressure levels are shown on the left vertical axis. The numbers inside the figure represent the mixing ratio of water vapor $\left(\mathrm{g} \mathrm{kg}^{-1}\right)$. Wind barbs are given on the right; half barb: $5 \mathrm{~m} \mathrm{~s}^{-1}$ and full barb: $10 \mathrm{~m} \mathrm{~s}^{-1}$ (created with the RadioSonde $\mathrm{R}$ package).

increased velocity reduces the saturation and furthers the negative buoyancy (and conversely), ensuring a negative feedback. The downdraft scheme contributes to the model-resolved tendencies of temperature, water vapor, and precipitation content (through Reynolds perturbations and source terms in the gridbox-averaged model equations).

\section{2) DIFFERENT MODEL RUNS}

The ALARO model of the RMI is used at 4-km grid spacing with the deep convective parameterization scheme 3MT. The model has been run with the unsaturated downdraft scheme (referred to as "fc4") and with the recalibrated unsaturated downdraft based on the cold pool characteristics (referred to as "fc4_tun"). These model runs were then evaluated using observations from radar and AWS. Since direct measurements of downdraft speeds were not available, we used results from a 1-km grid spacing run without a deep convective parameterization scheme (referred to as fc1) as a sanity check for the parameterized downdrafts.

The runs with 4-km grid spacing had 46 nonuniformly spaced vertical levels; the run with 1-km grid spacing had 60 vertical levels. Some features of the different simulations are listed in Table 1. Note that while the runs at 4-km grid spacing are hydrostatic, the parameterization allows nonhydrostatic processes and calculates the subgrid vertical motion in a prognostic way. Runs fc1, fc4, and fc4_tun were directly coupled to the global model ARPEGE.

\section{Description of the case}

\section{a. Synoptic-scale environment}

On 18 August 2011, an upper-level trough was present over the Atlantic Ocean with an axis south of Ireland (Fig. 2). Belgium and France were situated in the warm sector of a weak frontal system. A southerly flow 

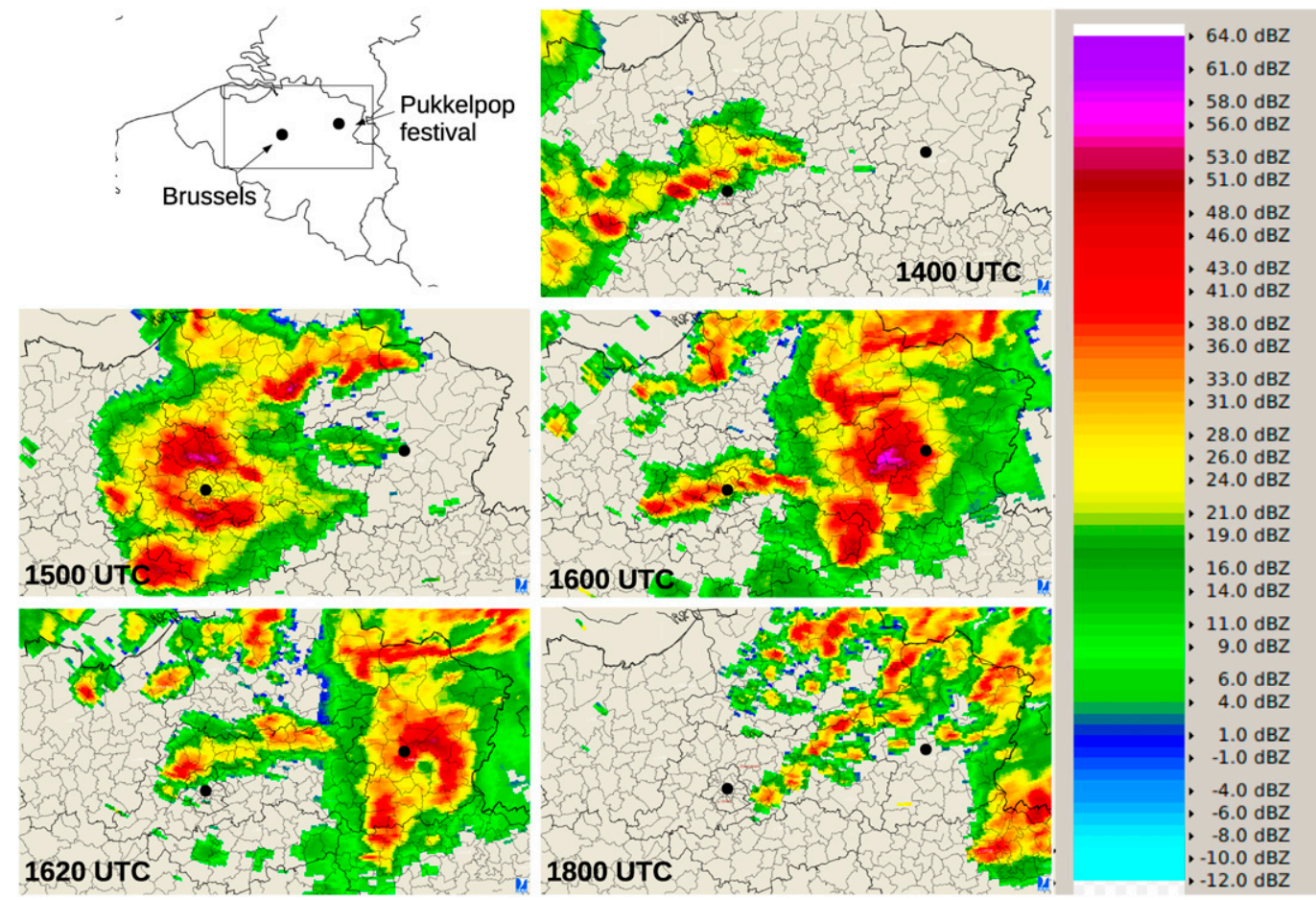

1800 UTC

FIG. 4. Radar reflectivity over a part of Belgium at 1400, 1500, 1600, 1620, and 1800 UTC. Two black dots mark the location of Brussels and the Pukkelpop festival. An elevation of $2^{\circ}$ is used since the bow echo was best visible at this elevation. The height of the scan corresponds to $6.6 \mathrm{~km}$ for Brussels and $5.4 \mathrm{~km}$ for the Pukkelpop festival.

advected unstable air northward. At low levels, the atmosphere was warm and very moist (2-m dewpoint reached $20^{\circ} \mathrm{C}$ ). In the warm sector, a thermal surface low was created in France, which moved northward while deepening under the influence of the solar heating and the approaching upper-level trough. In western Europe, thunderstorms are often created in such thermal lows (van Delden 1998). Moreover, thunderstorms are often associated with a "Spanish plume," which is an air mass originating from the Spanish Plateau (see e.g., Carlson and Ludlam 1968; van Delden 1998). A Spanish plume is characterized by steep lapse rates in the midtroposphere and dry air in a shallow layer around the $850-\mathrm{hPa}$ level. This layer of dry air, sometimes in combination with a weak inversion, prevents moist shallow convection. As a result, large amounts of water vapor can accumulate in the boundary layer, favoring the development of large cumulonimbus clouds if a forcing mechanism is present.

The prestorm environment was best captured by the sounding at Trappes, France (near Paris, see Fig. 1), at 0000 UTC 18 August 2011. It can be seen that the atmosphere was characterized by a steep lapse rate ina layer stretching from 900 to $300 \mathrm{hPa}$ (Fig. 3). Dry air was present between 900 and $800 \mathrm{hPa}$. This corresponds to the Spanish plume mentioned earlier. Some directional shear was present in the lowest levels, while moderate wind speed shear could be found aloft. The radiosonde data indicated a $0-6-\mathrm{km}$ bulk wind difference of $17 \mathrm{~m} \mathrm{~s}^{-1}$. The CAPE at 0000 UTC was only $160 \mathrm{~J} \mathrm{~kg}^{-1}$, but must have increased during the day (the model forecasted up to $1500 \mathrm{~J} \mathrm{~kg}^{-1}$ of CAPE at 1500 UTC; virtually no CAPE was predicted for the western part of the country due to frontal clouds preventing solar heating). The downdraft potential can be estimated from the downdraft convective available energy (DCAPE; Emanuel 1994), or from the difference in equivalent potential temperature (Atkins and Wakimoto 1991). The former is less useful for estimating the downdraft potential than CAPE is for the updraft, since the strongest downdrafts violate parcel theory [Gilmore and Wicker (1998); see also the discussion in Schultz and Askelson (2012)]. The latter is defined as (Atkins and Wakimoto 1991):

$$
\Delta \theta_{e}=\theta_{e, \max }-\theta_{e, \min }
$$

where $\theta_{e, \max }$ and $\theta_{e, \text { min }}$ stand for the equivalent potential temperature found at or just above the surface and the minimum value of equivalent potential temperature in the midlevels of the troposphere, 

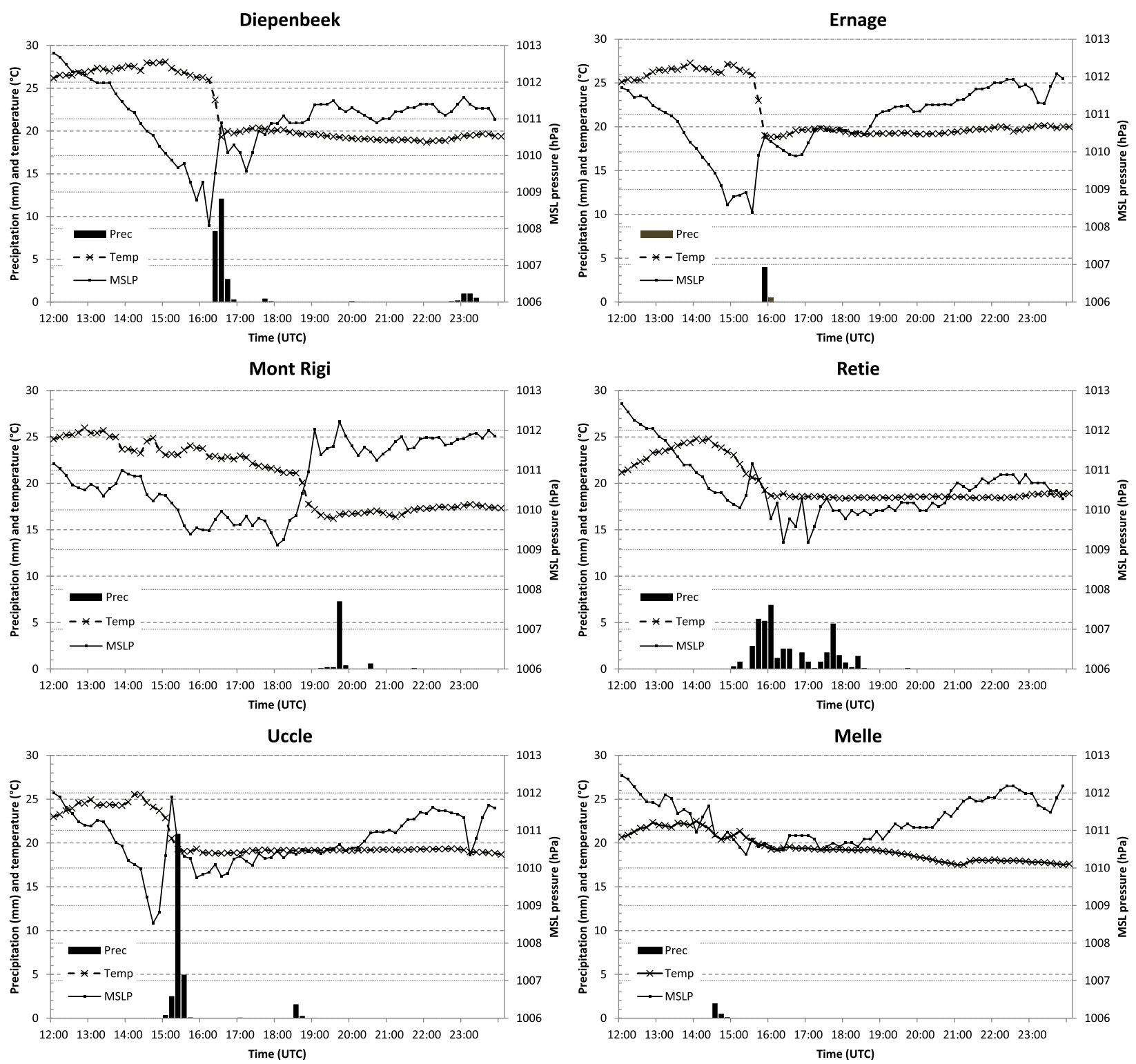

FIG. 5. The 2-m temperature $\left({ }^{\circ} \mathrm{C}\right.$, left vertical axis), mean sea level pressure (hPa, right vertical axis), and 10-min accumulated precipitation ( $\mathrm{mm}$, left vertical axis) as observed by six automatic weather stations over Belgium. A measurement has been made every 10 min.

respectively. The sounding in Trappes at 0000 UTC showed $\Delta \theta_{e}=18.8 \mathrm{~K}$. Atkins and Wakimoto (1991) found that the difference in the afternoon between the surface value of $\theta_{e}$ and the minimum value aloft was greater than $20 \mathrm{~K}$ for days with microbursts, whereas it was less than $13 \mathrm{~K}$ for the thunderstorm days with no microbursts.

\section{b. Radar evolution and precipitation}

Around 1300 UTC, several convective cells developed near the border of France and Belgium. The cells moved to the northeast and grew rapidly and were long lived (radar images are shown in Fig. 4). At 1510 UTC, the cells evolved into a bow echo with bookend vortex. The bookend vortex passed over Binkom (40 km east of Brussels, not shown) at 1550 UTC, where damage was observed due to severe wind gusts. Half an hour later, the bow echo passed over the music festival Pukkelpop. Several weaker cells developed afterward, and at 2000 UTC, most activity stopped. Enhanced IR satellite images showed cloud-top temperatures as low as $-60^{\circ} \mathrm{C}$; an overshooting top 

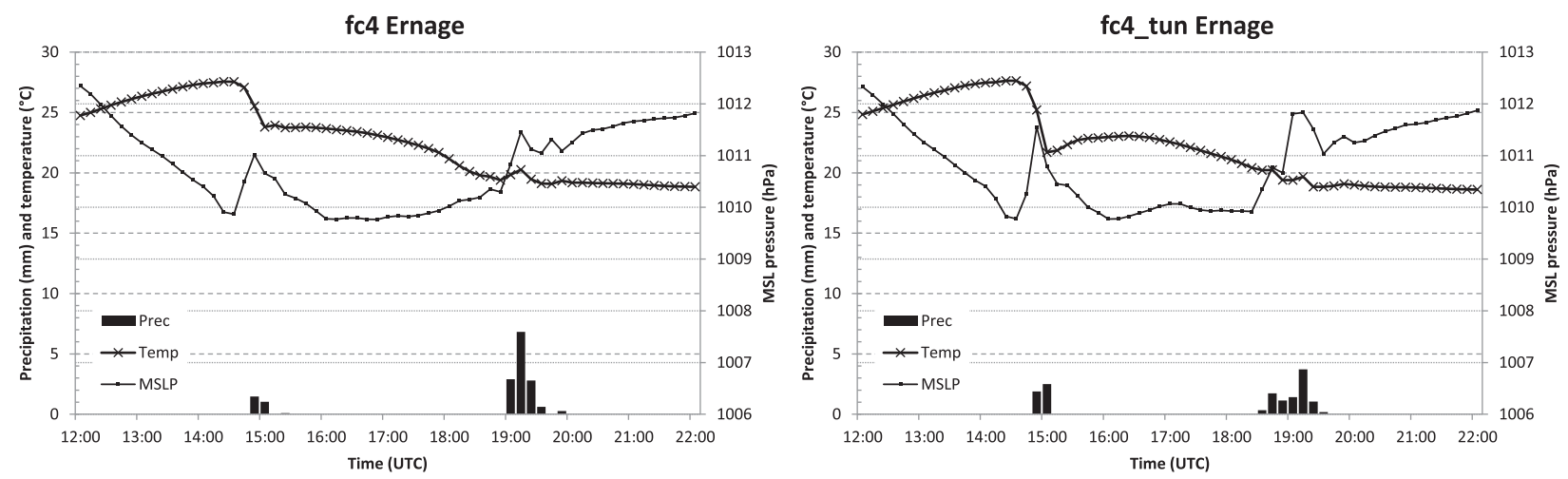

FIG. 6. Simulated 2-m temperature $\left({ }^{\circ} \mathrm{C}\right.$, left vertical axis), mean sea level pressure (hPa, right vertical axis), and precipitation (mm, left vertical axis) as predicted by (left) fc4 and (right) fc4_tun for a grid point corresponding with the AWS of Ernage, Belgium.

appeared clearly on the visible-channel satellite image (not shown).

\section{c. Cold pool and mesohigh}

Five AWSs in Belgium showed cold pools and associated mesohighs (data are shown in Fig. 5; to discriminate the convective signal from the synoptic-scale signal, data from the AWS of Melle, Belgium, are added, which was not hit by a thunderstorm). At these stations, a steady pressure drop was visible, which can be attributed to the approach of the thermal low, followed by a sharp pressure rise. The latter was accompanied by a steep decrease in temperature and the onset of precipitation. This pressure rise and
$2 \mathrm{~m} \mathrm{~T}\left({ }^{\circ} \mathrm{C}\right)$ fc4 $1800 \mathrm{UTC}$

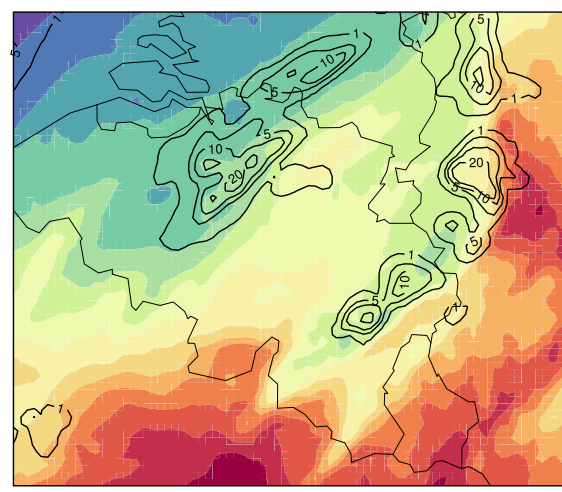

MSL pressure $(\mathrm{hPa})$ fc4 1800UTC

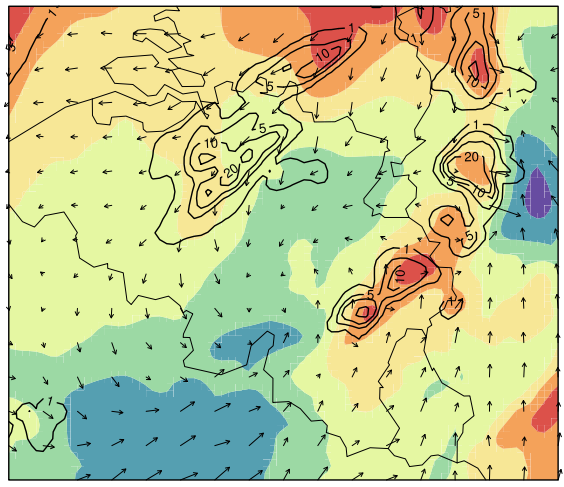

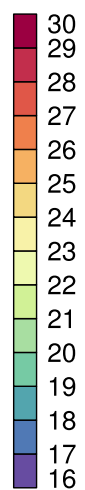

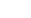

10125

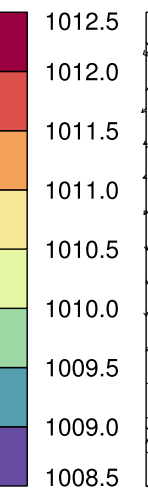

$2 m \operatorname{Td}\left({ }^{\circ} \mathrm{C}\right)$ fc4 $1800 \mathrm{UTC}$

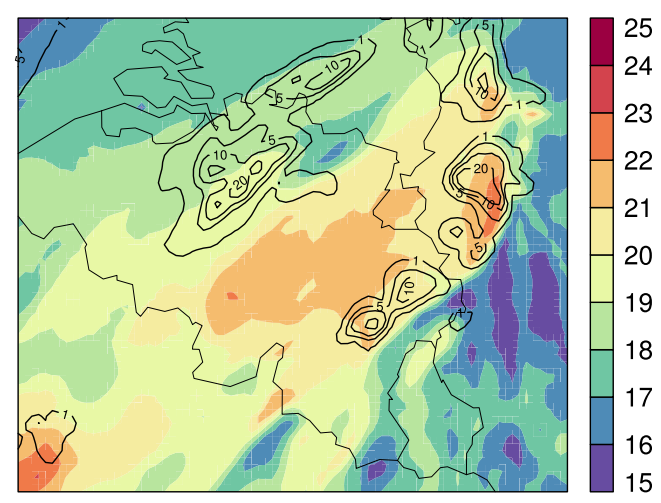

$10 \mathrm{~m}$ wind gusts $(\mathrm{m} / \mathrm{s})$ fc4 $1800 \mathrm{UTC}$

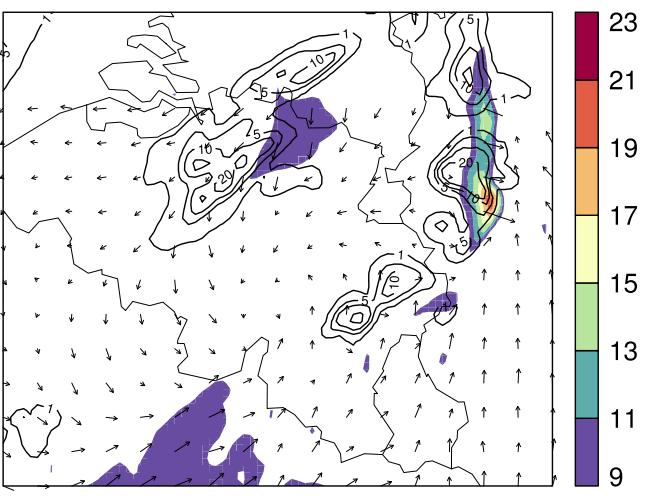

FIG. 7. The fc4 forecast for (top left) 2-m temperature $\left({ }^{\circ} \mathrm{C}\right)$, (top right) 2 -m dewpoint $\left({ }^{\circ} \mathrm{C}\right)$, (bottom left) mean sea level pressure $(\mathrm{hPa})$ with $10-\mathrm{m}$ wind vectors, and (bottom right) wind gust speed (colors, $\mathrm{m} \mathrm{s}^{-1}$ ) with wind gust vectors. The black contours represent rain rate (lines for $1,5,10,20$, and $50 \mathrm{~mm} \mathrm{~h}^{-1}$ ). 
$2 m$ T $\left({ }^{\circ} \mathrm{C}\right)$ fc4_tun 1800UTC

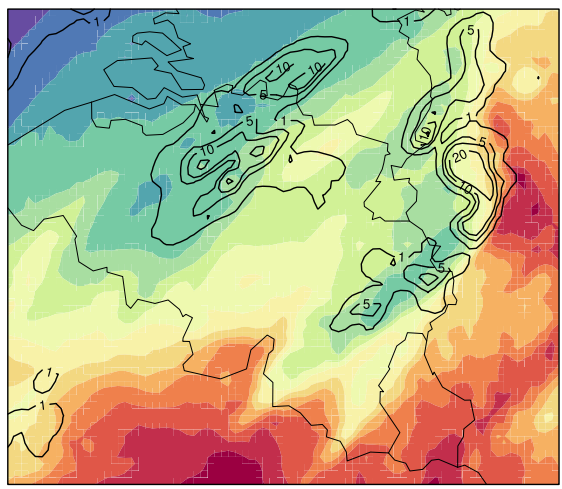

MSL pressure $(\mathrm{hPa})$ fc4 tun $1800 \mathrm{UTC}$

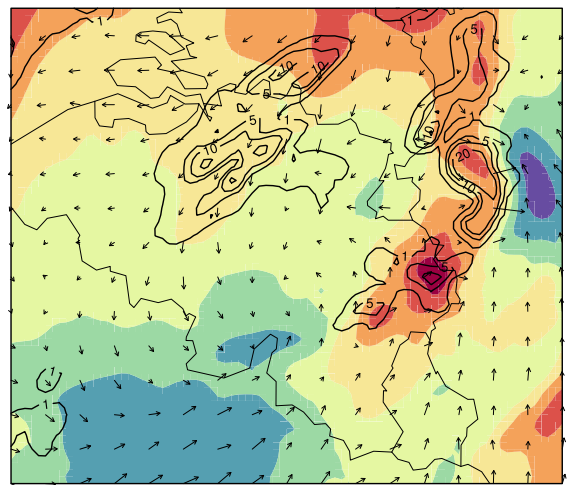

$2 m$ Td $\left({ }^{\circ} \mathrm{C}\right)$ fc4 tun $1800 \mathrm{UTC}$

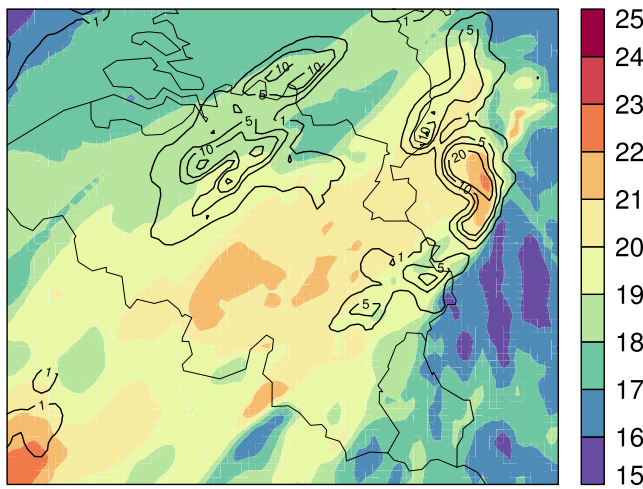

$10 \mathrm{~m}$ wind gusts $(\mathrm{m} / \mathrm{s})$ fc 4 tun $1800 \mathrm{UTC}$

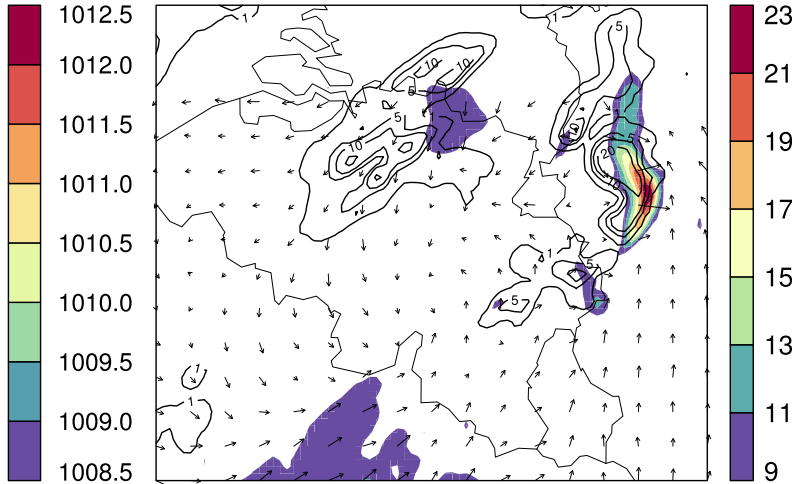

FIG. 8. As in Fig. 7, but as forecasted by fc4_tun.

temperature drop can be identified as the surface mesohigh and cold pool. The mean observed temperature drop was $6.4 \mathrm{~K}$, while the mean pressure rise was $2.4 \mathrm{hPa}$ (peak temperature drop of $7.4 \mathrm{~K}$ and peak pressure rise of $3.4 \mathrm{hPa}$ ). As noted in Engerer et al. (2008), the pressure rise is a better marker for the cold pool strength than the temperature drop, since the former is less sensitive to the diurnal cycle.

\section{Calibration of the unsaturated downdraft scheme}

Since no direct observations of the downdraft strength were available, secondary effects were needed to calibrate the unsaturated downdraft scheme. We compared observed cold pool strength with modeled cold pool strength, and changed the downdraft's entrainment and friction rate to improve the modeled cold pool.

The original version fc4 of the unsaturated downdraft scheme underestimated the temperature drop and pressure rise (e.g., see Fig. 6, left). We recalibrated entrainment and friction of the downdraft scheme in such a way that the forecasted cold pool strength corresponded best with the observations (Fig. 6, right). The calibrated value of the entrainment rate is $\mu=\lambda_{\mathrm{dd}} \times g=1.1 \times$ $10^{-5} \mathrm{~m}^{-1}$ in Eq. (5). There is a large uncertainty about the entrainment process in the downdraft (Knupp and Cotton 1985). Our value can be compared with the values estimated from laboratory experiments by Morton et al. (1956) [also used by Srivastava (1985)] who put forth a value of $\mu=0.2 / R$ that yields $2.0 \times 10^{-4} \mathrm{~m}^{-1}$ for an individual radius $R$ of $1 \mathrm{~km}$, and $2.0 \times 10^{-3} \mathrm{~m}^{-1}$ for an individual radius $R$ of $100 \mathrm{~m}$. The recalibrated friction $K_{\mathrm{dd}}$ is $1.85 \times 10^{-4} \mathrm{~m}^{-1}$, the original value was $3.0 \times$ $10^{-4} \mathrm{~m}^{-1}$, and the original entrainment rate $\mathrm{fc} 4$ was $\mu=3.9 \times 10^{-3} \mathrm{~m}^{-1}$.

Both fc4 and fc4_tun simulated a cold pool developing at 1600 UTC (not shown). The cold pool was well developed around 1800 UTC and strongest in the run with the calibrated downdraft scheme (Figs. 7 and $8)$. At that time, both runs forecasted the strongest wind gusts $\left(21 \mathrm{~m} \mathrm{~s}^{-1}\right.$ for $\mathrm{fc} 4$ and $23 \mathrm{~m} \mathrm{~s}^{-1}$ for fc4_tun). These peak wind gusts agree with the highest observed wind gust speed, which was $23 \mathrm{~m} \mathrm{~s}^{-1}$ (observed by the AWS of Diepenbeek), but is below the estimated wind gusts during the downburst ranging between 29 and $36 \mathrm{~m} \mathrm{~s}^{-1}$. In general, the run with the calibrated 
fc1 1300 UTC

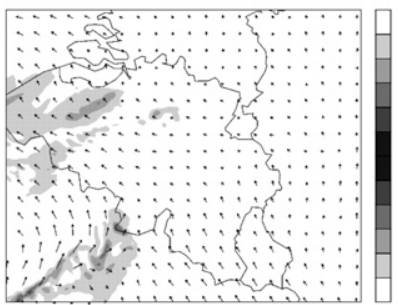

fC4 1300 UTC

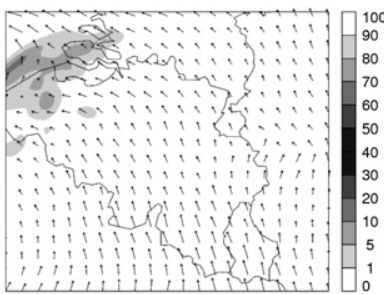

fC4_tun 1300 UTC

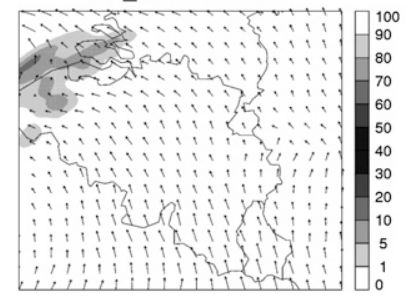

fc1 1500 UTC

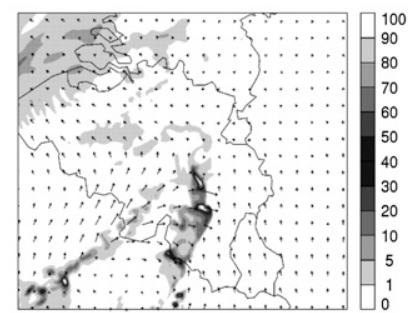

fC4 1500 UTC

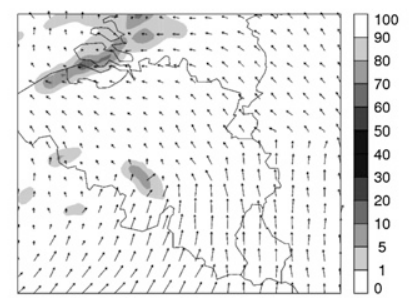

fc4_tun 1500 UTC

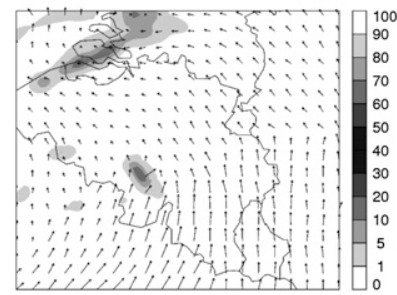

fc1 1700 UTC

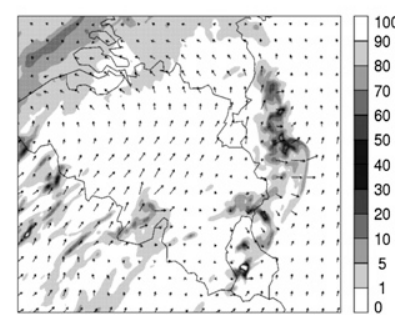

fC4 1700 UTC

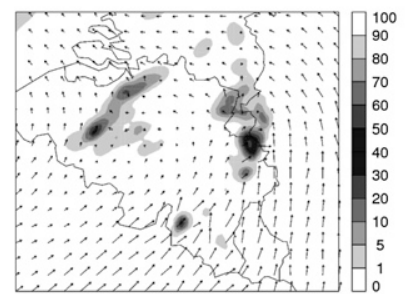

fc4_tun 1700 UTC

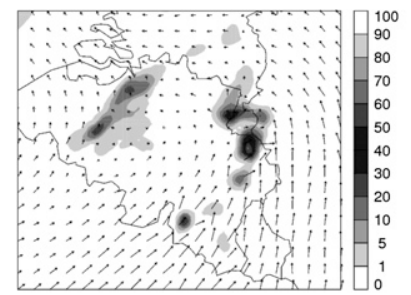

fc1 2200 UTC

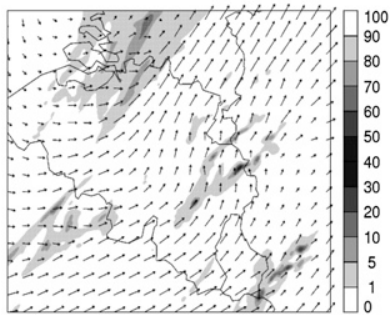

fc4 2200 UTC

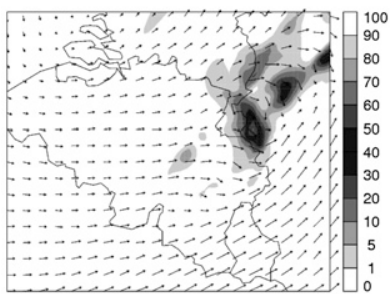

fC4_tun 2200 UTC

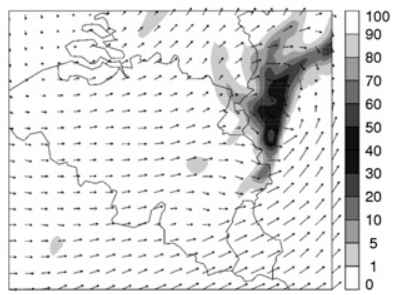

FIG. 9. The rain rate at 1300, 1500, 1800, and 2200 UTC forecasted by fc4, fc4_tun, and fc1. Wind vectors show the 925-hPa wind.

downdraft scheme predicted higher wind gusts (Figs. 7 and 8 ). The observed temperatures in the cold pool range from $17^{\circ}$ to $20^{\circ} \mathrm{C}$ (Fig. 5), which is lower than predicted by fc4 (temperature above $20^{\circ} \mathrm{C}$ in the cold pool, Fig. 7). Fc4_tun predicted a $1^{\circ}-2^{\circ} \mathrm{C}$ stronger cold pool over a wider area. The cold pool air was very close to saturation, with observed 2-m dewpoints of $18^{\circ}-$ $19^{\circ} \mathrm{C}$. Both fc4 and fc4_tun predicted too high $2-\mathrm{m}$ dewpoints. The predicted mean sea level pressure was smallest near the updraft and had a value below $1009 \mathrm{hPa}$. A mesohigh of $1011.5 \mathrm{hPa}$ was forecasted by fc4; fc4_tun forecasted a wider and slightly stronger mesohigh.

Run fc1 forecasted strong wind gusts along a "squallline"-like structure, with wind gust speeds between 30 and $40 \mathrm{~m} \mathrm{~s}^{-1}$ during 1500-1600 UTC. A stronger cold pool was predicted, with temperatures of $17^{\circ} \mathrm{C}$ and a mesohigh of $1014 \mathrm{hPa}$.

It was not possible to further calibrate the downdraft scheme to fully match the observed cold pool strength. For that, changes in the microphysics might be needed, such as an explicit treatment of hail [Srivastava (1987); hail with a diameter of $1-2 \mathrm{~cm}$ was observed during the downburst].
The simulations at the 4-km grid spacing with the deep convective parameterization scheme 3MT with unsaturated downdrafts ( $\mathrm{fc} 4$ and $\mathrm{fc} 4$ _tun) and at the 1-km grid spacing without $3 \mathrm{MT}$ ( $\mathrm{fc} 1$ ), predicted the precipitation satisfactorily (Fig. 9), compared to the values in the original operation runs with maxima of 5-10 mm. In fc1, deep convection started at 1300 UTC southwest of Belgium. The precipitation in the northwest of the domain is related to the cold front. At 1400 UTC, a squall-line-like structure was formed. Two very intense precipitation cores were present at 1500 UTC. The squall line, while increasing in size, decreased in intensity and left Belgium around 1700 UTC. Some smaller cells developed afterward. In fc4 and fc4_tun, convection started around 1500 UTC. The cells were most intense between 1700 and 1800 UTC. Around 1900 UTC, these cells left Belgium; at the same time, a second system was forming in the southwest of Belgium. This second system reached a peak intensity of around 2200 UTC (Fig. 9) and was too large compared to the small-scale cells detected by the radar (not shown).

The 24-h accumulated precipitation as forecasted by fc4, fc4_tun, and fc1, and as observed by the radar 

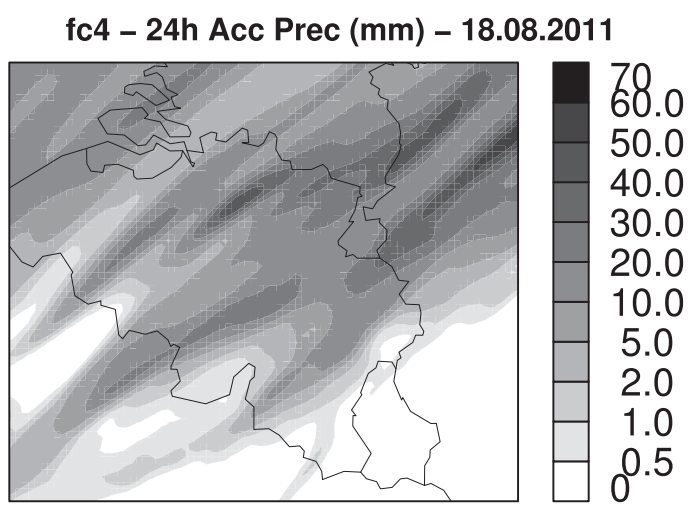

fc4_tun - 24h Acc Prec (mm) - 18.08.2011
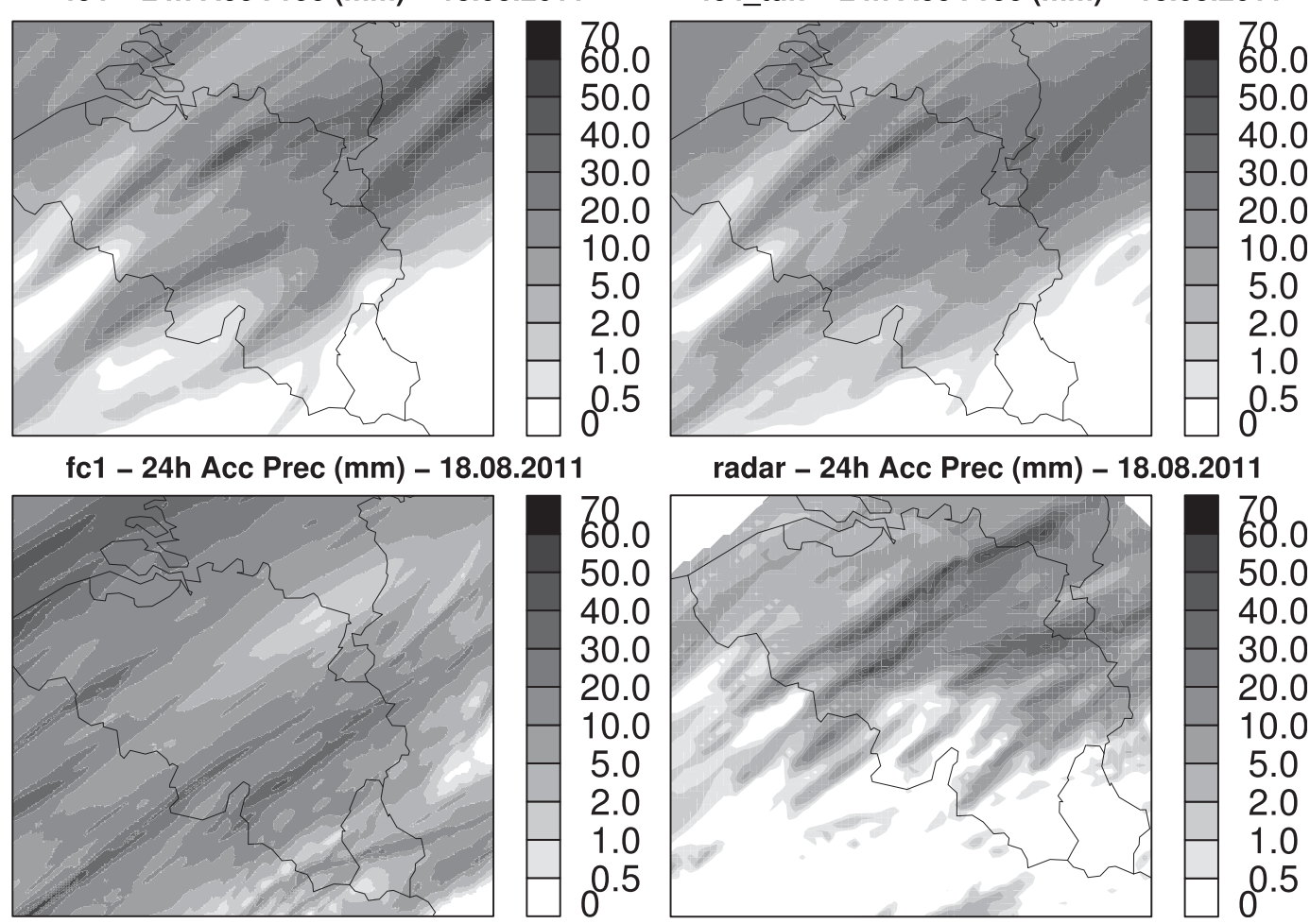

FIG. 10. The 24-h accumulated precipitation between 0000 and 2359 UTC 18 Aug 2011 as forecasted by fc4, fc4_tun, and fc1, and as observed by the radar of Wideumont.

can be seen in Fig. 10. Runs fc4 and fc4_tun predict nearly the same accumulated precipitation and both agree well with the radar observations in terms of quantity and location. In the fc1 run, precipitation has been shifted to the southwest of Belgium compared to radar observations, so that surprisingly, one could argue that the precipitation found in the fc4 runs was actually better than in $\mathrm{fc} 1$. The radar observed accumulated precipitation peaks up to $60 \mathrm{~mm}$, which is less than the $70-\mathrm{mm}$ peak measured by rain gauges. Signals at distances over $200 \mathrm{~km}$ away from the radar were considered unreliable and were therefore ignored, which explains why no precipitation is shown in the northwest and northeast of the domain.

\section{Downburst possibility}

The effect of the calibration on the downdrafts was tested. For a convenient analysis, the downdraft mass flux has been averaged over a layer between 1- and 3-km geopotential height. For the runs fc4 and fc4_tun, we considered the subgrid downdraft mass flux $(\omega / g)$ as given by the downdraft parameterization scheme, while for fc1, the grid-scale downward mass flux has been used. Every $12 \mathrm{~min}$ of the forecast, the largest downdraft mass flux has been selected and shown in Fig. 11 (top). Run fc4 predicted a downdraft mass flux around $1 \mathrm{~kg} \mathrm{~m}^{-2} \mathrm{~s}^{-1}$, with a peak at 1724 UTC of $1.25 \mathrm{~kg} \mathrm{~m}^{-2} \mathrm{~s}^{-1}$. Run fc4_tun predicted a downdraft mass flux between 2 and $3 \mathrm{~kg} \mathrm{~m}^{-2} \mathrm{~s}^{-1}$, with a peak at 1736 UTC of $4.83 \mathrm{~kg} \mathrm{~m}^{-2} \mathrm{~s}^{-1}$. Run fc1 predicted a downdraft mass flux between 3 and $4 \mathrm{~kg} \mathrm{~m}^{-2} \mathrm{~s}^{-1}$, with a peak at 1612 UTC of $5.29 \mathrm{~kg} \mathrm{~m}^{-2} \mathrm{~s}^{-1}$. High mass fluxes occurred earlier in the fc1 run, since convection initiated earlier.

The subgrid downdraft forecast at 1700 UTC is shown in Figs. $12 \mathrm{~b}$ and $12 \mathrm{c}$. When focusing on the precipitation at the eastern border of Belgium (which corresponds best to the observed downburstproducing bow echo in both timing and location), it can be seen that the recalibrated run forecasted strong subgrid downdrafts compared to fc4, which predicted only weak subgrid downdrafts in that region. Also, no strong downdrafts were forecasted in the precipitation cells in the northwest of Belgium, which agrees with the fact that (i) the conditions for convection were less favorable in that region and (ii) no wind damage was reported there. Furthermore, we see that reducing the downdraft entrainment and drag did not 

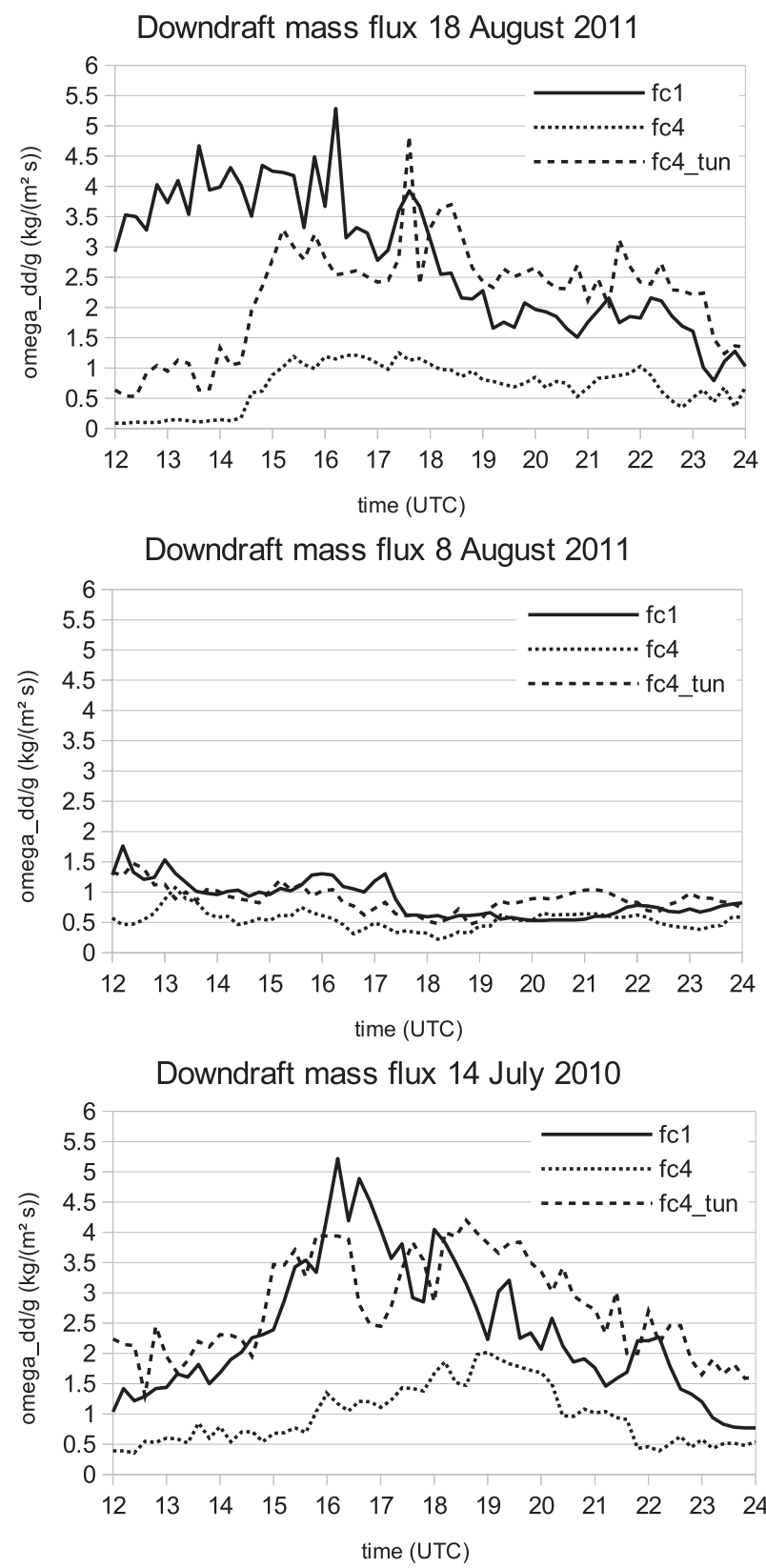

FIG. 11. Peak subgrid downdraft mass flux $\left(\mathrm{kg} \mathrm{m}^{-2} \mathrm{~s}^{-1}\right)$ as predicted by fc4, fc4_tun, and fc1 (data every $12 \mathrm{~min}$ ). (top) 18 Aug 2011, (middle) 8 Aug 2011, and (bottom) 14 Jul 2010

result in unrealistically large downdraft mass fluxes, because of the negative feedback inherent to the unsaturated downdraft representation (as discussed in section 2).

As an additional test, we did a systematic check of August 2011 and found several convective cases. Here we discuss the most pertinent case of 8 August 2011. It was characterized by small scattered convective showers (Fig. 13, top). The convective cells did not evolve into a mesoscale convective system and no cold pool or severe wind gusts were observed. We, therefore, expect that the calibrated downdraft scheme should not produce excessive subgrid mass fluxes. Run fc1 predicted a downdraft mass flux around $1 \mathrm{~kg} \mathrm{~m}^{-2} \mathrm{~s}^{-1}$, with peaks reaching $1.5 \mathrm{~kg} \mathrm{~m}^{-2} \mathrm{~s}^{-1}$ (Fig. 11, middle). Run fc4 predicted a mass flux of $0.5 \mathrm{~kg} \mathrm{~m}^{-2} \mathrm{~s}^{-1}$, with a peak of $1 \mathrm{~kg} \mathrm{~m}^{-2} \mathrm{~s}^{-1}$. For fc4_tun we see indeed that the predicted mass fluxes are not excessively high and are close to those predicted by fc1. Figures $12 \mathrm{e}$ and $12 \mathrm{f}$ show the subgrid downdraft mass flux forecast at 1500 UTC.

Last, we run fc4 and fc4_tun for another downburst case on 14 July 2010 (Fig. 13, bottom). A derecho passed over Belgium that day and produced multiple downbursts [see Hamid (2012) for a description]. Run fc1 predicted large mass fluxes, with a peak of $5.22 \mathrm{~kg} \mathrm{~m}^{-2} \mathrm{~s}^{-1}$ (Fig. 11, bottom). Run fc4_tun predicted slightly lower mass fluxes, with a peak of $4.20 \mathrm{~kg} \mathrm{~m}^{-2} \mathrm{~s}^{-1}$. Run fc4 predicted a peak mass flux of $2.02 \mathrm{~kg} \mathrm{~m}^{-2} \mathrm{~s}^{-1}$. Figures $12 \mathrm{~h}$ and $12 \mathrm{i}$ show the subgrid downdraft mass flux forecast at 1700 UTC.

The downdraft mass flux of the saturated downdraft scheme (for mesh fractions larger than 0.0005, i.e., $100-\mathrm{m}$ diameter in a $4 \mathrm{~km} \times 4 \mathrm{~km}$ grid box) is also shown in Figs. 12a, 12d, and 12g. It can be seen that the saturated downdraft scheme forecasted large $\omega / g$ in all regions with precipitation, even when we do not expect downbursts to be likely (for 18 August 2011: the precipitation in the northwest of the domain; for 8 August 2011: all precipitation cells; for 14 July 2010: the precipitation west of the squall line). Therefore, although the saturated downdraft gives satisfactory $\omega \times \sigma / g$, our choice to use $\omega / g$ as a proxy for downbursts does not give satisfactory results when applied to the saturated downdraft scheme.

It was also investigated whether the calibration of the downdraft affect the model performance. Runs fc4 and fc4_tun were validated during two test periods (August 2011 and August 2012) using radar data, AWS data, and model analyses (the latter was used for upper air verification). The model was initialized at 0000 UTC and produced forecasts for the next $36 \mathrm{~h}$.

At every 3-h lead time, the fc4 and fc4_tun forecasts were compared to observations from the AWS of Uccle, Belgium. The bias and root-meansquare error (rmse) were calculated for 2-m temperature, $2-\mathrm{m}$ relative humidity, and $30-\mathrm{m}$ wind speed and wind direction. It is found that for both 
fc4_satdd omega_dd/g $\left(\mathrm{kg} \mathrm{m}^{-2} \mathrm{~s}^{-1}\right)$

fc4 omega_dd/g $\left(\mathrm{kg} \mathrm{m}^{-2} \mathrm{~s}^{-1}\right)$
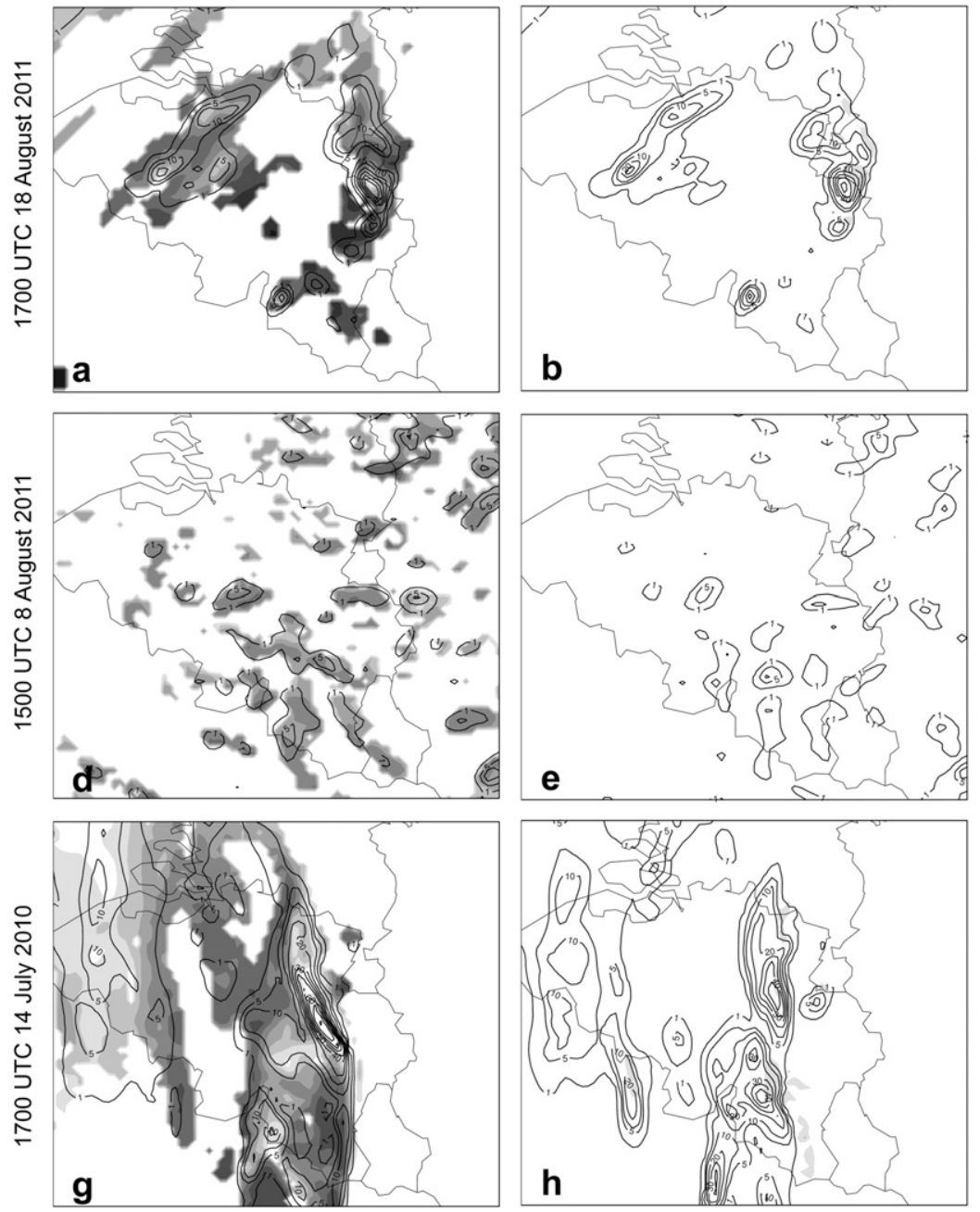

fc4_tun omega_dd/g $\left(\mathrm{kg} \mathrm{m}^{-2} \mathrm{~s}^{-1}\right)$
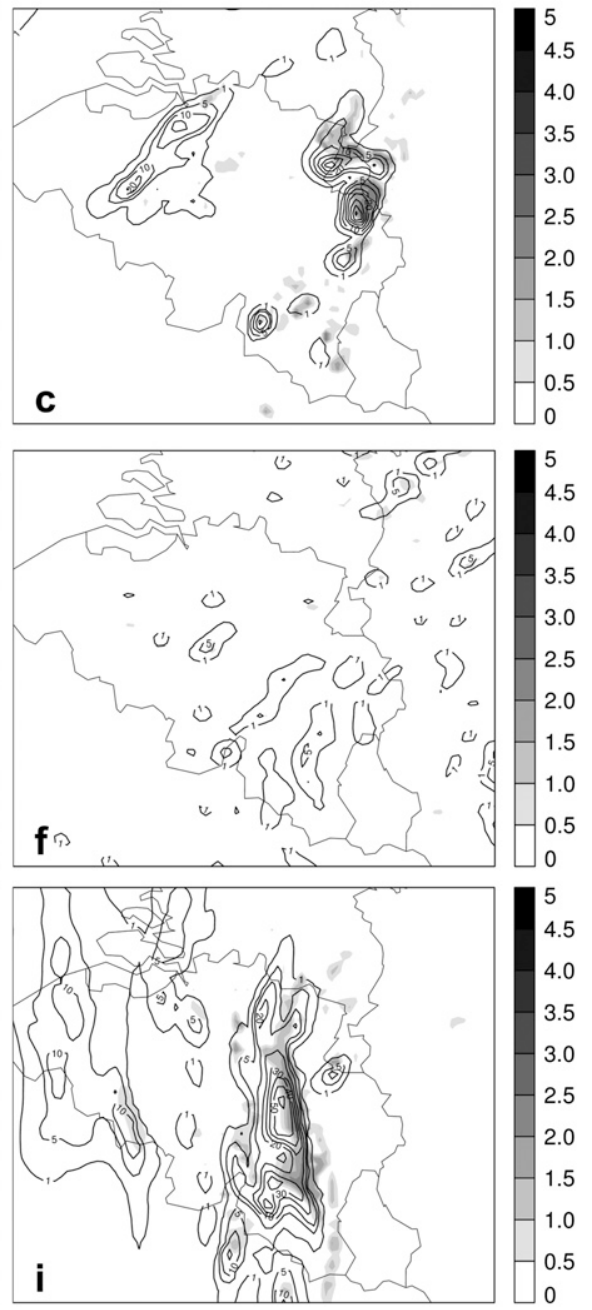

FIG. 12. Subgrid downdraft mass flux as forecasted by the saturated downdraft scheme (left) fc4_satdd and the unsaturated downdraft schemes, (middle) fc4, and (right) fc4_tun for (top) 1700 UTC 18 Aug 2011, (middle) 1500 UTC 8 Aug 2011, and (bottom) 1700 UTC 14 Jul 2010. The rain rate is shown by contours (lines for $1,5,10,20,30,40$, and $50 \mathrm{~mm} \mathrm{~h}^{-1}$ ).

validation periods, the scores are neutral (not shown).

From Figs. 9 and 10 it could already be seen that the precipitation forecast for the original and calibrated downdraft scheme is very similar. This is confirmed by the SAL scores for the two test periods. The SAL technique (Wernli et al. 2008) evaluates precipitation forecasts by comparing the structure $(S)$, amplitude $(A)$, and location $(L)$ of the predicted precipitation with the observed precipitation from radars. The $S$ and $A$ scores range from -2 to +2 $(S>0$ denotes that the predicted structure is too large or too flat; $A>0$ denotes that the predicted precipitation amount is too large). The location $L$ denotes how well the predicted precipitation is at the correct location and ranges from 0 (predicted precipitation at correct position) to 2 (predicted precipitation at incorrect position). Only precipitation events with a mean precipitation rate of at least $1 \mathrm{~mm}$ were selected (for August 2011: 20 days were selected; for August 2012: 11 days were selected). The SAL scores (weighted by precipitation amount) for fc4 and fc4_tun are very similar (Table 2).

The upper air forecast was validated by model analysis at every 6-h lead time. The rmse was computed for temperature, specific humidity, and wind at Uccle. No significant deterioration in the standard average model behavior was found (not shown). 

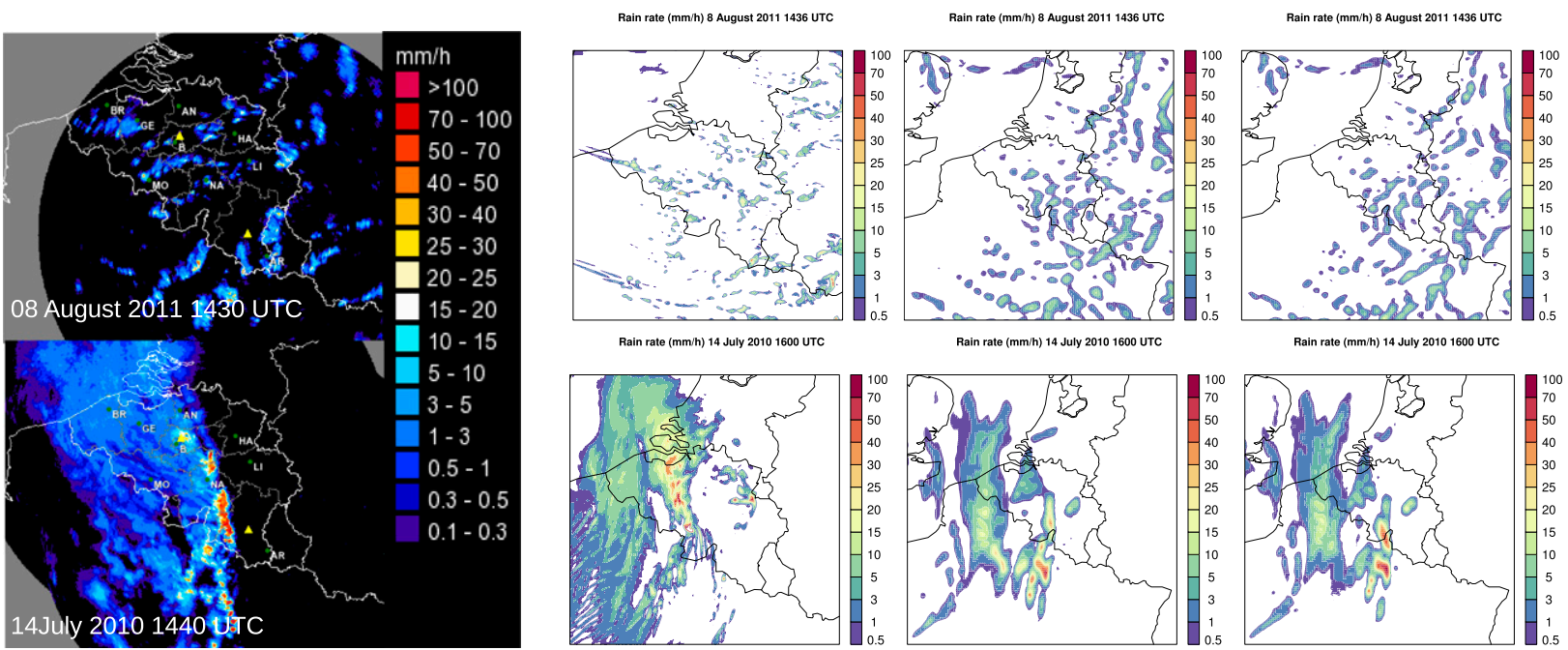

FIG. 13. (left) The rain-rate composite for (top left) 1430 UTC 8 Aug 2011 and (bottom left) 1440 UTC 14 Jul 2010, generated from the radars at Wideumont and Zaventem, Belgium (the position of the radars is shown by a yellow triangle). (right) The rain-rate forecast $\left(\mathrm{mm} \mathrm{h}^{-1}\right)$ as predicted by (left) fc1, (middle) fc4, and (right) fc4_tun for (top) 1436 UTC 8 Aug 2011 and (bottom) 1600 UTC $14 \mathrm{Jul} 2010$.

\section{Conclusions}

In this article, the predictability of small-scale downbursts was investigated using an operational forecast model running with a convection-permitting resolution. The occasion was a catastrophic case of a severe convective storm of 18 August 2011 causing five casualties at the Pukkelpop music festival in Belgium. The question addressed here was whether the downdrafts present in a parameterization scheme can be used as proxies for downbursts. Specifically, as a proxy for downbursts we propose to use the downdraft mass flux $\left(\omega_{\mathrm{dd}} / g\right)$.

The storm has been simulated using the operational ALARO model at 4-km grid spacing with a deep convective parameterization called $3 \mathrm{MT}$. The operational model used at that time in the RMI did not give a satisfactory behavior of precipitation rates and the downdrafts of the parameterization scheme of deep convection did not allow for the use of $\omega_{\mathrm{dd}} / g$ as indicator for short-lived downbursts.

An attempt was made to improve the situation in two steps. First, the scheme was completed with an unsaturated downdraft parameterization. Second, the details of the downdraft entrainment and friction were adapted to make the downdrafts more reactive in the cases that are known to us, where downbursts are expected.

As a result, the downdraft velocities were significantly improved in the case of the Pukkelpop event. Additionally, large downdraft velocities did not occur in cases where no downbursts were documented.
Also, the comparison with the 1-km grid spacing run showed that the fc4_tun downdrafts were not unrealistic.

Standard scores were computed and it was found that the changes in the model results were quite neutral. However, we acknowledge that additional tests (e.g., during winter) are necessary to get a full idea of the impact on the standard scores. Last, the adapted model version was tested for a past well-documented derecho case in 2010, finding the same improvements, and corroborating the results of the study period in 2011.

These results provide support to the idea that, with proper care, a parameterization scheme, or at least the studied 3MT scheme with unsaturated downdrafts used in this paper, can be calibrated to use the strength of the downdrafts as presented in the maps in Fig. 12 as an indicator of the possibility of downbursts in operational forecasts with NWP models running at today's kilometric resolutions.

TABLE 2. Structure, amplitude, and location $(S A L)$ scores for fc4 and fc4_tun.

\begin{tabular}{lcc}
\hline & fc4 & fc4_tun \\
\hline Aug 2011 & & \\
$S$ & 0.098 & 0.163 \\
$A$ & 0.302 & 0.271 \\
$L$ & 0.151 & 0.156 \\
Aug 2012 & & \\
$S$ & 0.377 & 0.415 \\
$A$ & 0.333 & 0.340 \\
$L$ & 0.209 & 0.202 \\
\hline
\end{tabular}


Acknowledgments. The authors thank the three anonymous reviewers for their constructive comments. Furthermore, we thank Maarten Reyniers for creating the radar reflectivity plots, Edouard Goudenhoofdt for providing radar and rain gauge data in Belgium, the Royal Netherlands Meteorological Institute (KNMI) for providing radar data from De Bilt, and the University of Wyoming for providing sounding data. The plots were made with the R software environment for statistical computing and graphics (http://cran.r-project.org/).

\section{REFERENCES}

Atkins, N. T., and R. M. Wakimoto, 1991: Wet microburst activity over the southeastern United States: Implications for forecasting. Wea. Forecasting, 6, 470-482, doi:10.1175/ 1520-0434(1991)006<0470:WMAOTS >2.0.CO;2.

— Processes that influence their damaging potential. Mon. Wea. Rev., 137, 1497-1513, doi:10.1175/2008MWR2649.1.

- J. M. Arnott, R. W. Przybylinski, and B. D. Ketcham, 2004: Vortex structure and evolution within bow echoes. Part I: Single-Doppler and damage analysis of the 29 June 1998 derecho. Mon. Wea. Rev., 132, 2224-2242, doi:10.1175/ 1520-0493(2004)132<2224:VSAEWB > 2.0.CO;2.

Betts, A. K., and M. F. Silva Dias, 1979: Unsaturated downdraft thermodynamics in cumulonimbus. J. Atmos. Sci., 36, 1061-1071, doi:10.1175/1520-0469(1979)036<1061:UDTIC > 2.0.CO;2.

Bryan, G. H., J. C. Wyngaard, and J. M. Fritsch, 2003: Resolution requirements for the simulation of deep moist convection. Mon. Wea. Rev., 131, 2394-2416, doi:10.1175/ 1520-0493(2003)131<2394:RRFTSO > 2.0.CO;2.

- D. Ahijevych, C. Davis, S. Trier, and M. Weisman, 2005: Observations of cold pool properties in mesoscale convective systems during BAMEX. Preprints, 11th Conf. on Mesoscale Processes, Albuquerque, NM, Amer. Meteor. Soc., JP5J.12. [Available online at https://ams.confex.com/ams/pdfpapers/96718.pdf.]

Carlson, T. N., and F. H. Ludlam, 1968: Conditions for the occurrence of severe local storms. Tellus, 20, 203-226, doi:10.1111/ j.2153-3490.1968.tb00364.x.

Delobbe, L., and I. Holleman, 2006: Uncertainties in radar echo top heights used for hail detection. Meteor. Appl., 13, 361-374, doi:10.1017/S1350482706002374.

Deng, A., and D. R. Stauffer, 2006: On improving 4-km mesoscale model simulations. J. Appl. Meteor. Climatol., 45, 361-381, doi:10.1175/JAM2341.1.

De Troch, R., R. Hamdi, H. Van de Vyver, J.-F. Geleyn, and P. Termonia, 2013: Multiscale performance of the ALARO-0 model for simulating extreme summer precipitation climatology in Belgium. J. Climate, 26, 8895-8915, doi:10.1175/ JCLI-D-12-00844.1.

Emanuel, K. A., 1994: Atmospheric Convection. Oxford University Press, $580 \mathrm{pp}$

Engerer, N. A., D. J. Stensrud, and M. C. Coniglio, 2008: Surface characteristics of observed cold pools. Mon. Wea. Rev., 136, 4839-4849, doi:10.1175/2008MWR2528.1.

Fujita, T. T., 1959: Precipitation and cold air production in mesoscale thunderstorm systems. J. Meteor., 16, 454-466, doi:10.1175/ 1520-0469(1959)016<0454:PACAPI > 2.0.CO;2.

- 1981: Tornadoes and downbursts in the context of generalized planetary scales. J. Atmos. Sci., 38, 1511-1534, doi:10.1175/ 1520-0469(1981)038<1511:TADITC > 2.0.CO;2.
—_ and R. M. Wakimoto, 1983: Microbursts in JAWS depicted by Doppler radars, PAM, and aerial photographs. Preprints, 21th Conf. on Radar Meteorology, Edmonton, Alberta, Canada, 638-645.

Gerard, L., 2007: An integrated package for subgrid convection, clouds and precipitation compatible with the meso-gamma scales. Quart. J. Roy. Meteor. Soc., 133, 711-730, doi:10.1002/qj.58.

— J.-M. Piriou, R. Brožková, J.-F. Geleyn, and D. Banciu, 2009: Cloud and precipitation parametrization in a meso-gammascale operational weather prediction model. Mon. Wea. Rev., 137, 3960-3977, doi:10.1175/2009MWR2750.1.

Gilmore, M. S., and L. J. Wicker, 1998: The influence of midtropospheric dryness on supercell morphology and evolution. Mon. Wea. Rev., 126, 943-958, doi:10.1175/ 1520-0493(1998)126<0943:TIOMDO>2.0.CO;2.

Hamid, K., 2012: Investigation of the passage of a derecho in Belgium. Atmos. Res., 107, 86-105, doi:10.1016/j.atmosres.2011.12.013.

Johnson, R. H., and P. J. Hamilton, 1988: The relationship of surface pressure features to the precipitation and airflow structure of an intense midlatitude squall. Mon. Wea. Rev., 116, 1444-1473, doi:10.1175/1520-0493(1988)116<1444:TROSPF>2.0.CO;2.

Knupp, R. K., and W. R. Cotton, 1985: Convective cloud downdraft structure: An interpretative survey. Rev. Geophys., 23, 183215, doi:10.1029/RG023i002p00183.

Morton, B. R., G. I. Taylor, and J. S. Turner, 1956: Turbulent gravitational convection from maintained and instantaneous sources. Proc. Roy. Soc. London, 234, 1-23, doi:10.1098/rspa.1956.0011.

Schultz, C. J., and M. A. Askelson, 2012: Vertical variations of boundary layer potential buoyancy in tornadic and nontornadic near-storm environments. Wea. Forecasting, 27, 1489-1506, doi:10.1175/WAF-D-11-00097.1.

Srivastava, R. C., 1985: A simple model of evaporatively driven downdraft: Application to microburst downdraft. J. Atmos. Sci., 42, 1004 1023, doi:10.1175/1520-0469(1985)042<1004:ASMOED>2.0.CO;2. , 1987: A model of intense downdrafts driven by the melting and evaporation of precipitation. J. Atmos. Sci., 44, 1752-1774, doi:10.1175/1520-0469(1987)044<1752:AMOIDD>2.0.CO;2.

Sud, Y. C., and G. K. Walker, 1993: A rain evaporation and downdraft parameterization to complement a cumulus updraft scheme and its evaluation using GATE data. Mon. Wea. Rev., 121,3019-3039, doi:10.1175/1520-0493(1993)121<3019:AREADP>2.0.CO;2.

van Delden, A., 1998: The synoptic setting of a thundery low and associated prefrontal squall line in western Europe. Meteor. Atmos. Phys., 65, 113-131, doi:10.1007/BF01030272.

Vescio, M., and R. Johnson, 1992: The surface-wind response to transient mesoscale pressure fields associated with squall lines. Mon. Wea. Rev., 120, 1837-1850, doi:10.1175/1520-0493(1992)120<1837: TSWRTT $>2.0 . \mathrm{CO} ; 2$

Wakimoto, R. M., 1982: The life cycle of thunderstorm gust fronts as viewed with Doppler radar and rawinsonde data. Mon. Wea. Rev., 110, 1060-1082, doi:10.1175/1520-0493(1982)110<1060 TLCOTG $>2.0 . C O ; 2$.

- , H. V. Murphey, C. A. Davis, and N. T. Atkins, 2006: High winds generated by bow echoes. Part II: The relationship between the mesovortices and damaging straight-line winds Mon. Wea. Rev., 134, 2813-2829, doi:10.1175/MWR3216.1.

Wernli, H., M. Paulat, M. Hagen, and C. Frei, 2008: SAL-A novel quality measure for the verification of quantitative precipitation. Mon. Wea. Rev., 136, 4470-4487, doi:10.1175/2008MWR2415.1.

Wheatley, D. M., and R. J. Trapp, 2008: The effect of mesoscale heterogenity on the genesis and structure of mesovortices within quasi-linear convective systems. Mon. Wea. Rev., 136, 4220-4241, doi:10.1175/2008MWR2294.1. 